\title{
MÔ HìNH MẬT Độ VỎ TRÁI ĐẤT \\ LÃNH THỔ VIỆT NAM
}

\author{
CAO Đình TRIÊU
}

Viện Vật lý địa cằ

\begin{abstract}
Summary. Gravity inverse problems of $2 D$ and $3 D$ have been used by the author for studying the density model of the Earth crust and adjoined to upper Mantle boundary in the territory of Vietnam.
\end{abstract}

\section{Mở DẦU}

Các kết quả mới nhất về cấu trúc vỏ trải đất lãnh thỗ Việt Nam đã được đề cập trong công trình $[2,3]$. Do thiếu số liệu đo sâu địa vật lý (địa chấn đo sâu, điện từ telua...), các nghiên cứu này chủ yếu dựa trên cơ sở phân tích tài liệu trọng lực và từ hàng không, có tham khảo kết quả phân tích sóng động đất nghiên cứu đặc trưng phân lớp vỏ tại vùng trạm địa chấn Hoà bình, Tuyên quang, Bắc giang, Sapa và Phủ liễn.

Trong khuân khổ công trình này tác giả giải bài toán trọng lực hai chiều với mô hỉnh lớp mặt phằng đút đoạn nằm ngang và bải toán trọng lực ba chiều với mô hình cấu trúc khối hộp chữ nhật tìm hiểu quy luật biến đổi mật độ vơ và cận ranh giới vỏ thượng manti. Các nghiân cứu trước đây $[1,2]$ cũng được tác giả sử dụng trong thiết lập mô hình giải bài toán ngược trọng lực. Tỷ lệ nghiên cứu là 1:2 000000 .

\section{CO' SỞ TÀI LIỆU VÀ PHƯONG PHÁP PHÂN TÍCH}

\subsection{Tài liệu}

Tài liệu chủ yếu được sử dụng trong nghiên cứu này là bản đồ dị thường trọng lực bouguer tỷ lệ $1: 500000$ và $1: 1000000$ do Tồng cục địa chất thành lập năm 1985, các tuyến trọng lực tỷ lệ 1:200 000 (1) thành phố Hồ Chí Minh - Hà nội, (2) Hoà bình - Hà nội - Lạng sơn do Trung tâm nghiên cứu vật lý địa cầu trước đây thành lập trong giai đoạn 1979-1985 (lưu trữ tại Viện Vật lý địa cău). Ngoài ra tác giả còn tham khăo thêm thông số vật lý của đát đá, bản đồ địa chất Việt nam tŷ̉ lệ 1:1000 000 do Tổng cục địa chất thành lập năm 1985 (lưu trữ tại Viện Vật lý địa cầu) và bản đồ phân vùng địa cấu trúc [4]. 


\subsection{Phương pháp phân tích số liệu}

\subsubsection{Bài toán trọng lực hai chiều}

Dị thường trọng lực gây nên bởi khối bất đồng nhất mật độ được xác lập trên cơ sớ công thức của Bulac $\mathrm{E}$. G. [1]

$$
\begin{array}{r}
\Delta g(x)=K \sum_{j=1}^{m} \sigma_{j}\left[\pi\left(H-j-h_{j}\right)+2 H_{j} \operatorname{arctg} \frac{x-d_{j}}{H_{j}}-\right. \\
\left.2 H_{j} \operatorname{arctg} \frac{x-d_{j}}{h_{j}}+\left(x-d_{j}\right) \ln \frac{H_{j}^{2}+\left(x-d_{j}\right)^{2}}{h_{j}^{2}+\left(x-d_{j}\right)^{2}}\right]
\end{array}
$$

ớ đây $K$ hệ số hấp dẫn trọng lực, $m$ số lượng các lớp mặt phăng đứt đoạn được phân chia với các thông số: $h_{j}$ độ sâu tới các mặt ranh giới phía trên, $H_{j}$ độ sâu tới các mặt ranh giơi phía dưới, $\sigma_{j}$ mật độ dư, $d_{j}$ toạ độ của ranh giới thẳng đứng so với toạ độ xác định dị thường.

Để tìm nghiệm của bài toán ngược ta thiết lập hàm

$$
F=\sum_{i=1}^{n}\left[\Delta g_{m}\left(x_{i}, y_{i}\right)-\Delta g_{j}\left(x_{i}, y_{i}\right)\right]^{2}
$$

\subsubsection{Bài toán trọng lực ba chî̀u}

- Trong trường hợp này công thức tính dị thường trọng lực có dạng [1]

$$
\begin{aligned}
\Delta_{i}(x, y) & =-K \sum_{j=1}^{m} \sigma_{j}\left\{-\left(d_{j}-x\right) \ln \frac{\left[\left(l_{2 j}-y\right)+A_{j}^{22}\right]\left[\left(l_{1 j}-y\right)+A_{j}^{11}\right]}{\left[\left(l_{1 j}-y\right)+A_{j}^{12}\right]\left[\left(l_{2 j}-y\right)+A_{j}^{21}\right]}\right. \\
& +\left(l_{2 j}-y\right) \ln \frac{\left(d_{j}-x\right)+A_{j}^{21}}{\left(d_{j}-x\right)+A_{j}^{22}}-\left(l_{1 j}-y\right) \ln \frac{\left(d_{j}-x\right)+A_{j}^{11}}{\left(d_{j}-x\right)+A_{j}^{12}} \\
& +H_{j}\left[\operatorname{arctg} \frac{H_{j}}{l_{2 j}-y}-\operatorname{arctg} \frac{H_{j} A_{j}^{22}}{\left(d_{j}-x\right)\left(l_{2 j}-y\right)}-\operatorname{arctg} \frac{H_{j}}{l_{1 j}-y}+\operatorname{arctg} \frac{H_{j} A_{j}^{12}}{\left(d_{j}-x\right)\left(l_{1 j}-y\right)}\right] \\
& -h_{j}\left[\operatorname{arctg} \frac{h_{j}}{l_{2 j}-y}-\operatorname{arctg} \frac{h_{j} A_{j}^{22}}{\left(d_{j}-x\right)\left(l_{2 j}-y\right)}-\operatorname{arctg} \frac{h_{j}}{l_{1 j}-y}+\operatorname{arctg} \frac{h_{j} A_{j}^{12}}{\left(d_{j}-x\right)\left(l_{1 j}-y\right)} \mid\right\}
\end{aligned}
$$

ở đây: $\sigma_{j}, h_{j}, H_{j}, l_{1 j}, l_{2 j}, d_{j}$ là các thông số cưa khối hộp chữ nhật,

$$
\begin{aligned}
& A_{j}^{11}=\sqrt{\left(d_{j}-x\right)^{2}+\left(l_{1 j}-y\right)^{2}+h_{j}^{2}} \\
& A_{j}^{12}=\sqrt{\left(d_{j}-x\right)^{2}+\left(l_{1 j}-y\right)^{2}+H_{j}^{2}} \\
& A_{j}^{21}=\sqrt{\left(d_{j}-x\right)^{2}+\left(l_{2 j}-y\right)^{2}+h_{j}^{2}} \\
& A_{j}^{22}=\sqrt{\left(d_{j}-x\right)^{2}+\left(l_{1 j}-y\right)^{2}+H_{j}^{2}} .
\end{aligned}
$$


Tương tự như trong bài toán trọng lực hai chiều, nểu ta cho $d_{j}=d$ và $l_{1 j}, l_{2 j}$ có thể xác định trước trên cơ sở cấu trúc của dị thường trọng lực Bouguer thì công thức (3) sẽ được rút gọn và tính toán $\Delta g_{t}(x, y)$ sẽ đơn giản hơn. Nghiệm của bài toán ngược trọng lực sẽ là nghiệm cực tiểu của phiếm hàm

$$
F=\sum_{i=1}^{n}\left[\Delta_{m}\left(x_{i}, y_{i}\right)-\Delta_{t}\left(x_{i}, y_{i}\right)\right]^{2}
$$

2.2.3. Nghiệm của phương trình (2) và (4) được xác lập trên cơ sở phương pháp đường dốc nhất. Nó được mô tá bằng phương pháp lặp sau [5]:

$$
U^{(L+1)}=U^{(L)}-\varepsilon_{L} \operatorname{grad} F\left(U^{(L)}\right)
$$

̛̛ đây $U=(\sigma, h, \ldots) ; \operatorname{grad} F(U)=(\partial F / \partial \sigma, \partial F / \partial h, \ldots), \varepsilon_{L}$ là dãy tham số lặp, nó được chọn sao cho phương pháp đường dốc nhất trong trường hợp này hội tụ. Sự hội tụ được đảm bảo bời định lý về hội tụ xem trong [5].

\subsubsection{Xác lập mô hình mật độ}

Mô hinh mật độ vỏ trái đất được thiết lập trên cơ sớ kết quả giải bài toán ngược trọng lực nghiên cứu khối bất đồng nhất mật độ, kết hợp với các thông số mật độ cưa đất đá trầm tích trên bề mặt và lỗ khoan sâu cũng như phân tích vận tốc truyền sóng động đất [3]

\section{MÔ HİNH MẬT Dộ VỎ TRÁI DÂT}

Trên cơ sở thuật toán trinh bày trên tác giả đã thiết lập mô hỉnh mật độ vỏ trái đất lãnh thỗ Việt nam bao gồm: (1) mật độ lớp cơ bản vỏ trái đất (trầm tích, "granit", "Bazan" và thượng manti) và ranh giới giữa chúng; (2) phân loại đứt gãy theo độ sâu ảnh hưởng của chúng trong việc phân chia ngang mật độ vỏ trái đất và thượng manti.

3.1 Mặt móng kết tinh và mật độ lớp trầm tích

Nhìn chung mặt móng kết tinh lãnh thỗ nghiên cứu biến đổi khá phức tạp, từ lộ ra trên bề mặt tới độ sâu $8-10 \mathrm{~km}$ (hình 1 ). Vùng sụt lún sâu nhất của mặt móng này trùng với: (1) trung tâm trũng Hàn nội (chỉ số IV) đạt tới 8-10km; (2) trung tâm trũng Tú lệ (VI) (hc=7-8km); (3) trung tâm trũng Đà lạt (XIII) (hc=5-6km). Ranh giới này phản ánh sự thay đôi chênh lệch giữa lớp trầm tích và lớp granit biến đồi trong phạm vi từ $0.06 \mathrm{~g} / \mathrm{cm} 3$ đến $0.08 \mathrm{~g} / \mathrm{cm} 3$. 
Mật độ trung bình lớp phủ trầm tích lãnh thổ nghiên cứu đạt giá trị $2.61-2.63 \mathrm{~g} / \mathrm{cm} 3$ và biến đổi như sau:

- Đới cấu trúc Đà lạt (XIII), trũng Hà nội (IV), cấu trúc Ninh bình (V) và trũng Tú lệ (VI) có giá trị trung bình mật độ lớp trầm tích là $2.61 \mathrm{~g} / \mathrm{cm} 3$ (bảng 1 ).

- Giá trị trung bình mật độ $2.62 \mathrm{~g} / \mathrm{cm} 3$ đặc trưng cho đới uốn nếp Đông bắc (III), đới Mường tè (VII), sông Mã - Thanh hoá (VIII), Nghệ tînh (X), An điền (XI), Cửu long (XIV) và Minh hải-.Kiên giang (XV).

- Dới uốn nếp Cao bằng (I), Hà giang (II), địa khới phú hoạt (IX) và địa khối Kontum được đặc trưng bởi mật độ trung bỉnh lớp trầm tích cao, đạt $2.63 \mathrm{~g} / \mathrm{cm} 3$.

\subsection{Ranh giới mật dộ "granit" - "Bazan" (mặt Canrad).}

Ranh giới này biểu hiện sự chênh lệch mật độ trung bình lóp "granit" là 2.68$2.70 \mathrm{~g} / \mathrm{cm} 3$ và lớp "Bazan” là 2.80-2.90 $\mathrm{g} / \mathrm{cm} 3$ (bảng 1 ).

Các đứt gãy sâu xuyên vỏ là ranh giới phân chia ngang mật độ lớp "granit". Chằng hạn, mật độ trung bỉnh lớp này đạt $2.68-2.69 \mathrm{~g} / \mathrm{cm} 3$ tại các đới uốn nếp Mezozoi (Đà lạt (XIII), Tú lệ (VI)) và đới uốn nêp kainozoi (Hà nội (IV), Cứu long (XIV)). Trong khi đó đối với địa chất và khối nâng giá trị trung bình mật độ lớp "granit" đạt $2.70 \mathrm{~g} / \mathrm{cm} 3$.

Độ sâu mặt ranh giới này biến đổi khá phức tạp, tạo thành các cấu trúc dương dạng giải phương Tây bắc - Đông nam là chủ yếu. Đó là cấu trúc Hà nội (IV), sông Mã - Thanh hoá (VIII), Cửu long (XIV) giá trị độ sâu mặt móng này là nhỏ hơn $12 \mathrm{~km}$. Cấu trúc Hà giang có độ sâu mặt Conrad lớn nhất, có thể đạt tới $22-24 \mathrm{~km}$. Các cấu trúc còn lại giá trị độ sâu mặt ranh giới này biến đổi trong phạm vi $12-20 \mathrm{~km}$ vơi $x u$ hướng tăng dần về phía trung tâm trũng uốn nếp Mezozoi (Tú lệ (VI)), Đà lạt (XIII) và địa khối (Phú hoạch (IX), Kontum (VIII)).

3.3. Ranh giới mật độ vỏ-thượng manti (Mật Mohorovicic)

Nhỉn chung độ sâu mặt ranh giới mật độ vó - thượng manti biến đổi trong giới hạn $30-38 \mathrm{~km}$ và có $x u$ hướng chìm dần theo phương Tây băc, về phía trung tâm, đói uốn nếp Mezozoi, địa khối và nâng dần về phia trung tâm đói uốn nếp kainozoi. Các cấu trúc chính mặt ranh giới này có phương Tây bắc - Đông nam là chư yếu và bao gồm:

- Cấu trúc dương: (1) Hà nội (IV) $\left(h_{M}=30 \mathrm{~km}\right)$, (2) sông Mã - Thanh hoá $\left(h_{M}=\right.$ $30-34 \mathrm{~km})$ (VIII), Cưu long (XIV) $\left(h_{M}=30 \mathrm{~km}\right)$.

- Cấu trúc âm: (1) Tú lệ (VI) $\left(h_{M}=30-36 \mathrm{~km}\right)$ và Đà lạt (XIII) $\left(h_{M}=34-36 \mathrm{~km}\right)$.

Ranh giới này biểu hiện sự chênh lệch mật độtrung bình lớp Bazan là $2.88-2.90 \mathrm{~g} / \mathrm{cm} 3$ và thượng manti là $3.14-3.28 \mathrm{~g} / \mathrm{cm} 3$ (bảng 1 ). 


\subsection{Mật độ thượng manti}

Mật độ thượng manti lãnh thổ nghiên cứu đạt giá trị $3.14-3.28 \mathrm{~g} / \mathrm{cm} 3$ (hình 2) và nó biểu hiện biến đổi ngang rõ nét. Tại các đới uốn nếp Mezozoi và Kainozoi (trũng Hà nội (IV), trũng Tú lệ (VI), trũng An điền (XI), trũng Đà lạt (XIII), trũng Cứu long (XIV) giá trị mật độ thượng manti chỉ đạt3.14-3.15g/cm3. Trong khi đó tại địa khối Phú hoạt (IX), Kontum (XII), đới nâng Hà giang (II), đới nâng sông Mã - Thanh hoá (VIII) giá trị trung bỉnh mật độ đạt lớn hơn $3.20 \mathrm{~g} / \mathrm{cm} 3$ (bảng 1 ). Tại các đới còn lại như Đông bắc (I), Mường tè (VII), Nghệ tînh (X), Minh hải - Kiên giang giá trị trung bình mật độ lớp này nằm trong giới hạn $3.18-3.20 \mathrm{~g} / \mathrm{cm} 3$. Đóng vai trò ranh giơi ngang mật độ thượng manti là các đứt gãy sâu: (1) Cao bằng - Lạng sơn, (2) Hà giang, (3) Đông triều - Cẫm phà, (4) sông Hồng, (5) Lai châu - Điện biên, (6) Sơn la, (7) sông Mã, (8) sông Că, (9) Sơn trà, (10) Trà mi, (11) Tuy hoà - Orang, (12) Vûng tàu - Lộc ninh, sông Hậu, (14) Thuận hải - Minh hải, (15) Rạch giá.

\section{KẾT LUẬN}

Trên cơ sở kết quả nghiên cứu của công trình này có thể rủt ra một số kết luận sau:

1. Mặt ranh giới mật độ vờ-thượng manti lãnh thổ Việt nam có độ sâu biến đổi trong giới hạn $30-38 \mathrm{~km}$ và hình thành các cấu trúc dương, âm phương Tây băc Đông nam là chư yếu. Cấu trúc dương mặ̆t ranh giới này trùng với các đới nâng sông Mã, sông Hồng, trũng địa hào kainozoi Hà nội, Cửu long. Trong khi đó các cấu trúc âm phù hợp với đới uốn nếp Mezozoi (Tú lệ, Đà lạt) và địa khối (Phú hoạt Kon tum).

2. Có biểu hiện biến đỗi ngang mật độ vỏ trái đất và thượng manti trong lãnh thổ Việt nam. Giá trị trung bình mật độ vỏ trái đất thấp trùng với đới uốn nếp Mezozoi, Kainozoi và ngược lại, mật độ trung bình lớn hơ đặc trưng cho đới uốn nếp Đông băc, Hà giang (vùng rìa nền Hoa nam) và địa khối (Phú hoạt, Kon tum).

3. Các đứt gãy sâu lãnh thồ Việt nam bao gồm: Cao bằng - Lạng sơn , Hà giang Đông triều - Cầm phá, sông Hồng, Lai châu - Điện biên, Sơn la, sông Mã, sông Cá, Sơn trà, Trà mi, Tuy hoà - Orang, vũng tàu - Lộc ninh, sông Hậu, Thuận hải - Minh hải và Rạch giá. Độ sâu xuyên cắt của các đứt gãy này là lớn hơn 60 km. 
Giá trị trung bình các lớp cơ bán vỏ thượng manti

\begin{tabular}{|c|c|c|c|c|c|}
\hline $\begin{array}{l}\text { Chí } \\
\text { số }\end{array}$ & Dơn vị cấu trúc & $\begin{array}{l}\text { Lớp trầm } \\
\text { tích } \\
(\mathrm{g} / \mathrm{cm} 3)\end{array}$ & $\begin{array}{l}\text { Lớp } \\
\text { "Granit" } \\
\text { (g/cm3) }\end{array}$ & $\begin{array}{l}\text { Lớp } \\
\text { "Bazan" } \\
\text { (g/cm3) }\end{array}$ & $\begin{array}{l}\text { Thượng } \\
\text { manti } \\
(\mathrm{g} / \mathrm{cm} 3)\end{array}$ \\
\hline I & Cao bằng & 2.63 & 2.70 & 2.90 & 3.26 \\
\hline II & Hà giang & 2.63 & 2.70 & 2.90 & 3.26 \\
\hline III & Dông bắc & 2.62 & 2.69 & 2.90 & 3.25 \\
\hline IV & Trũng Kainozoi Hà nội & 2.61 & 2.68 & 2.88 & 3.14 \\
\hline V & Ninh binh & 2.61 & 2.70 & 2.90 & 3.17 \\
\hline VI & Trũng Mezozoi Tú lệ & 2.61 & 2.68 & 2.90 & 3.15 \\
\hline VII & Mường tè & 2.62 & 2.68 & 2.89 & 3.19 \\
\hline VIII & Sông mã Thanh hoá & 2.62 & 2.69 & 2.89 & 3.28 \\
\hline $\mathrm{X}$ & Nghệ tînh & 2.62 & 2.68 & 2.89 & 3.16 \\
\hline XI & Trũng An điền & 2.62 & 2.69 & 2.89 & 3.15 \\
\hline XII & Địa khối kon tum & 2.63 & 2.70 & 2.90 & 3.23 \\
\hline XIII & Trũng Mezozoi Đà lạt & 2.61 & 2.69 & 2.89 & 3.15 \\
\hline XIV & Trũng Cưu long & 2.62 & 2.68 & 2.90 & 3.14 \\
\hline XV & Minh hải Kiến giang & 2.62 & 2.68 & 2.89 & 3.18 \\
\hline
\end{tabular}

- Sơ đồ cấu trúc mặt móng kết tinh: (1) đường thằng độ sâu; (2) nới lộ mặt móng trên bề mặt, (3) đơn vị cấu trúc (như mô tả trong hỉnh (2), (4) đứt gãy sâu (như mô tả trong hinh 2).

Sơ đồ cấu trúc mặt ranh giới mật độ Conral: (1) đường thẳng độ sâu (contour intarval $2 \mathrm{~km}$ ), (2) đứt gãy sâu (như mô tả trong hình 2), (3) đơvị cấu trúc (như mô tả trong hinh 2).

Sơ đồ cấu trúc mặt ranh giơi Mohorovicic: (1) đường thẳng độ sâu contour $2 \mathrm{~km}$ ), (2) đơvị cấu trúc (như mô tả trong hỉnh 2), (3) đứt gãy sâu (như mô tả trong hỉnh 2).

Mô hình mật độ thượng manti: (1) đơn vị cấu trúc, I - Cao bằng, II - Hà giang, III - Đông bắc, IV - Hà nội, V - Ninh bình, VI - Tú lệ, VII Mường tè, VIII - sông mã Thanh hoá, IX - Phú hoạt, X - Nghệ-tînh, XI - An điền, XII - Kon tum, XIII - Đà lạt, XIV - Cứu long, XV - Minh hải - Kiên giang, (2) giá trị mật độ: Đứt gãy cấp I, (1) Cao bằng - Lạng sơn, (2) Hà giang, (3) Đông triều - Cẩm phá, (4) sông Hồng, (5) Lai châu Điện biên, (6) Sơn la, (7) Sông Mã, (8) sông Cá, (9) Sơn trà, (10) trà mi, (11) Tuy hoà - 
Orang, (12) Vũng tàu - Lộc ninh, (13) sông Hậu, (14) Minh hải - Thuận hải, (15) Rạch giá.

\section{TÀI LIỆU THAM KHẢO}

1. Bulax E.G. Hệ thống phân tích tự động hoá dị thường trọng lực, Naukadumka, Kiev, 1973 132tr. (tiếng $\mathrm{Nga}$ ).

2. Cao Đinh Triều, Deep structure and characteristics of seismic activity on the territory of Vietnam, Hanoi 1991, $140 \mathrm{p}$.

3. Cao Đình Triều và Hoàng Văn Vượng, Tìm hiểu quy luật biến đổi mật độ vó trái đất lãnh thố Việt nam và ưng dụng nó trong phân tích tài liệu trọng lực, Tuyễn tập công trình vật lý địa cầu, tập V (1985-1986), Hà nội 179-183.

4. Phạm Huy Long, Phân vùng địa chất lãnh thổ Việt nam, Hội nghị địa chất lần thứ hai, Proceed. Hà nội 1985, 75-85.

5. Vainberg M.M., Phương pháp biến phân và phương pháp toán tử đơn điệu, 1972, 332 tr. (tiếng $\mathrm{Nga}$ ). 


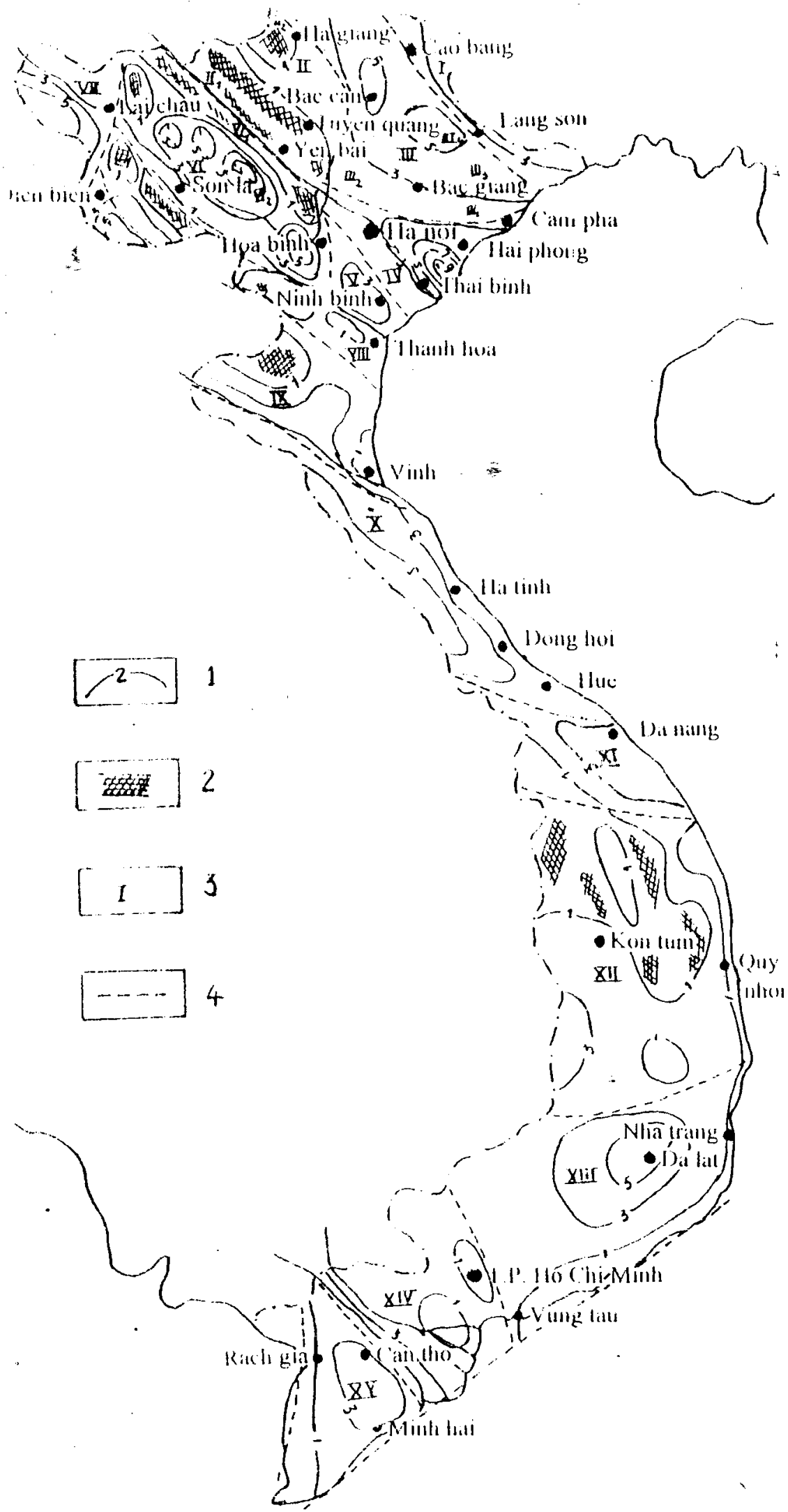




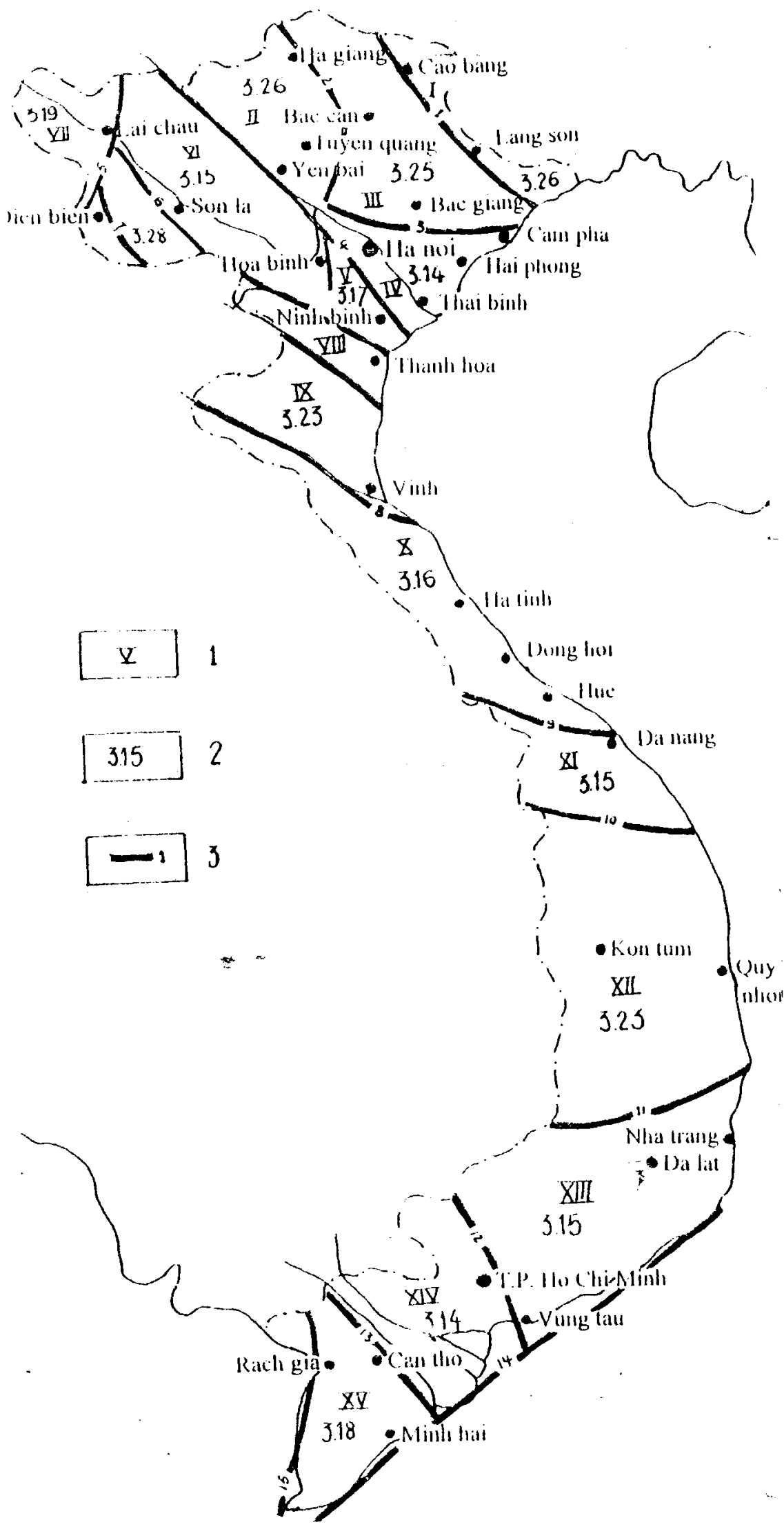

